\title{
Coupling Action of Cooling and Dynamic Load Impact on Deformation Characteristics of High-Salinity Saline Soils
}

\author{
Yu Zhang $\mathbb{D}^{1}{ }^{1}$ Meisi Zou, ${ }^{2}$ Runze Tian, ${ }^{1}$ Anhua $\mathrm{Xu},{ }^{3}$ Yunlong Hou, ${ }^{4}$ Bingbing Han, ${ }^{4}$ \\ and Xuemei $\mathbf{L i}^{5}$ \\ ${ }^{1}$ School of Traffic and Transportation, Lanzhou Jiaotong University, Lanzhou 730070, China \\ ${ }^{2}$ School of Automotive Engineering, Jiujiang Vocational and Technical College, Jiujiang 332005, China \\ ${ }^{3}$ Qinghai Communications Technical College, Xining 810003, China \\ ${ }^{4}$ Gansu Institute of Engineering Geology, Lanzhou 730000, China \\ ${ }^{5}$ Faculty of Geomatics, Lanzhou Jiaotong University, Lanzhou 730070, China
}

Correspondence should be addressed to Yu Zhang; zhangyu@mail.lzjtu.cn

Received 20 June 2021; Revised 4 August 2021; Accepted 16 August 2021; Published 11 September 2021

Academic Editor: Xudong Zhang

Copyright (c) $2021 \mathrm{Yu}$ Zhang et al. This is an open access article distributed under the Creative Commons Attribution License, which permits unrestricted use, distribution, and reproduction in any medium, provided the original work is properly cited.

In order to grasp the characteristics and mechanism of saline soil deformation under the coupling action of cooling and dynamic load, three types of subgrade fillings from the Qarhan-Golmud Highway in Qinghai-Tibet Plateau were selected as experimental soil samples for the experimental study. Firstly, the freezing temperature experiment was carried out on SS (sandy silt) and HS (high-sulfate silty clay). The test results showed that the freezing temperature of $\mathrm{SS}$ is $-0.32^{\circ} \mathrm{C}$, while that of $\mathrm{HC}$ (high-chloride silty clay) and HS will not freeze at $-20^{\circ} \mathrm{C}$, due to the presence of salt. Secondly, the three soil samples were subjected to deformation characteristic test under coupling action of cooling and dynamic load, respectively, and the time history curve of temperature gradient change, the time history curve of the change rate of deformation, and deformation rate were summarized. Finally, the model of deformation rate vs. time and the model of change rate of deformation vs. deformation rate under the coupling action of cooling and dynamic load are proposed. The test results found that (1) the cooling rate of the temperature gradient curve of the three soil samples showed a rapid cooling rate in the early stage, and it tends to stabilize in the later stage. The distance of the $0^{\circ} \mathrm{C}$ line from the top gradually decreases, which is affected by the freezing temperature and the salt content. (2) Affected by the freezing temperature and salt type, SS exhibits frost heave, and HS and HC appear to settlement. The final deformation is $1.0 \%,-0.73 \%$, and $-1.10 \%$, respectively. (3) The model of deformation rate vs. time and the model of change rate of deformation vs. deformation rate under the coupling action of cooling and dynamic load were proposed and verified, which are helpful for the evaluation of engineering stability on saline soil subgrade fillings.

\section{Introduction}

In recent years, with the rapid development of China's economy, traffic construction occupies an increasingly important position. At present, motor vehicle ownership continues to rise, which also makes more and more scholars begin to pay attention to the study of the impact of deformation of roadbed pavement by traffic load. The number of projects carried out on traffic construction is rapidly increasing, and the scale of the projects is getting bigger and wider, so more and more geotechnical problems are manifested. These geotechnical engineering problems are mainly caused by two kinds of reasons: the deformation caused by the weak foundation resistance or its own foundation bearing capacity is low. Therefore, it is important to study the upper load of foundation and the deformation and strength of geotechnical engineering.

Akoto and Singh [1] determined the elastic and viscoelastic parameters of lime-improved red clay through cyclic triaxial tests and analyzed the effect of dynamic load on the modulus of resilience. $\mathrm{Xu}$ and Zhou [2] studied the shape of saturated soft clay under undrained cyclic loading, measured the pore water pressure of different cycles under cyclic loading, and established a characteristic suitable for 
saturated soft clay in Shanghai. Pritz [3] conducted dynamic triaxial liquefaction tests on undisturbed loess and remolded loess in the eastern United States under constant-amplitude cyclic loading and obtained the same liquefaction standards and failure standards of saturated loess as Prakash. Zhang [4] improved the expansive soil, using quicklime as the improver. Both the plain soil and the improved soil have been tested with static load and dynamic load, and a more comprehensive understanding of the engineering properties of lime-improved expansive soil has been obtained. Li and Zhou [5] conducted a dynamic study on fly ash type subgrade fillers and proposed that the vibration frequency, initial static stress level, and water content are all influencing factors of the dynamic strength of fly ash. Zhang et al. [6] conducted freeze-thaw cycle experiments on sulfate saline soils with $1.0 \%$ salt content and studied soil deformation, and the experimental results showed that salt crystallization was the main influencing factor of soil deformation. Wang et al. [7] conducted freezing experiments on chloride saline soils with salinity in the range of $0.1 \%-1 \%$ and concluded that it is not considered constant whether the soil system is in a frozen state, which should depend on soil texture, moisture, salinity, etc. Darrow et al. [8] conducted frost swelling tests on five natural fine-grained soils under a load of $200 \mathrm{kPa}$, and the experimental results showed that soils with colloidal organic components removed became less susceptible to frost. From the above studies, it can be found that most of the current studies on deformation characteristics of subgrade fillers and related load experiments are for nonsaline soils under frozen conditions or saline soils with low salt content, and there are few experimental studies on deformation of highly chlorinated saline soils under nonfrozen conditions.

Zhang et al. [9] conducted top freezing experiments for saline soils with $0.6 \%$ salt content. It was found that the temperature in the frozen zone changed faster than that in the unfrozen zone, and a model was developed to describe the coupled hydro-thermal-salt-mechanical (HTSM) process. Tian et al. [10] conducted deformation tests on a railroad roadbed fill in Inner Mongolia under the coupling effect of load and temperature and found that both static and dynamic loads had a certain inhibitory effect on soil frost swelling, and the frost swelling rate of this fine-grained soil gradually decreases with increasing external load values. Zhou [11] and Ye and Lai [12] studied soft clay and Hangzhou Bay silty soil, respectively, and found that the greater the vibration frequency, the smaller the dynamic strain generated by the sample and the higher the dynamic strength. Zhou [13] also used the stress-controlled cyclic triaxial test and found that the soil damage value is related to the cyclic stress ratio. At the same time, the test also found that the cyclic stress value is the main factor affecting the generation and growth of cyclic pore water pressure. Matesic and Vucetic [14] studied the effect of strain rate on the dynamic secant modulus under the condition of small strain for three types of clays and three types of sands. Khosla and Singh [15] conducted a series of cyclic loading tests on air-dry Ottawa sand and studied the influence of the number of loadings on the strain. As the number of cyclic loading increases, the sand will appear in three strain states. Sarkar and Mishra [16] established a saline soil erosion sensitivity model using binary logistic regression algorithm and artificial neural network. Zhang et al. [17] used BP neural network to influence the effect of expansion load on the suppression effect of salt expansion of 6 different types of output saline soil, including fine-grained soil gravel sulfate saline soil and fine-grained soil gravel sulfite saline soil. Zhao et al. [18] took saline soil as the research object; based on the British GDS dynamic triaxial test system, the freezing triaxial test was carried out under the temperature change state, and its dynamic stress-dynamic strain and dynamic shear modulus and other changing laws were studied under different temperature, frequency, and confining pressure. Zhang et al. [19, 20] investigated the effect of hydrothermal behavior on the frost swelling of saturated chalky clay soils. Four different pressures were applied to the top of each soil sample. Experimental results showed that the recharge water was the main component of the frost swelling. The increased applied pressure can limit the water migration and reduce the frost swelling during soil freezing and proposed that the frost swelling behavior of saturated chalk soil during unidirectional freezing is related to many factors, such as soil properties, water content, soil sample size, and environmental conditions. Previous studies have mostly focused on the dynamic load mechanical properties of nonfrozen soil under low-temperature environments and the factors affecting soil deformation. Few studies have focused on the deformation of nonfrozen saline soils with different salt types under coupled action of the cooling process and the dynamic loads.

Saline soils exist in most parts of China, including the Songnen Plain, Huang-Huai-Hai Plain, the coastal areas, the Hetao area of Inner Mongolia, and the inland areas of Northwest China $[21,22]$. Especially in the western part of China, there are a large number of low-grade roads and rural roads, which are affected by climate, technology, and economic factors, and some of them have frost swelling and slurry diseases, which seriously affect the transportation business of China and even affect the pace of development of western China. A total number of geotechnical properties of subgrade soil should be investigated. According to the geotechnical properties and chemical analysis of soil samples from more than 200 sampling points along the QarhanGolmud Highway, the saline soil in this area is mostly lowplasticity fine clay (CL), with a salt content ranging from $0.2 \%$ to $48.5 \%$. Chloride ion content is mainly concentrated at about $3 \%$ to $25 \%$, and the sulfate ion content is basically stable around $0.3 \%$ to $2 \%$ in the whole process [23]. The salt content and the salt type directly affect the mechanical behavior of saline soil; the two typical high-chlorine saline soil and high-sulfur saline soil are selected as the research objects. Through the experimental study on the deformation of representative soil samples under the coupling effect of cooling and dynamic load, the deformation laws and adaptability of saline soil of different salt types are summarized, which are sufficient reference for the selection of subgrade soil in similar areas. 

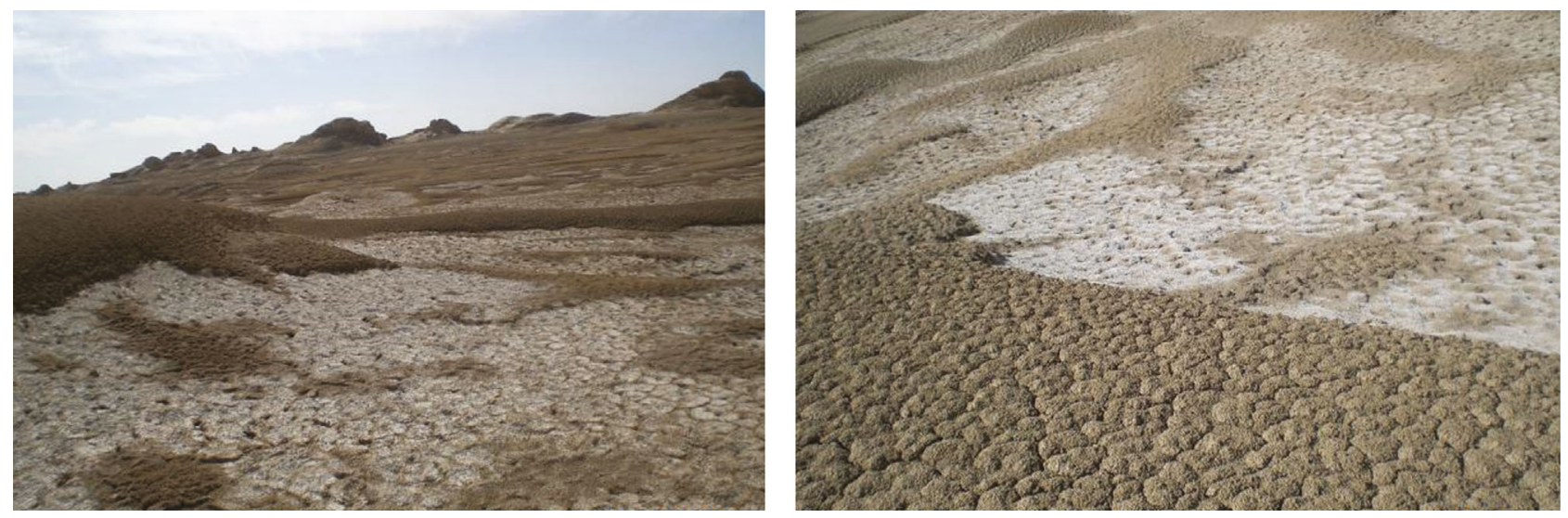

Figure 1: View of a high-salinity soil sampling site along the Qarhan-Golmud Highway. Photo taken in April 2021.

TABle 1: Physical property parameters of the test soil sample.

\begin{tabular}{lccccccc}
\hline Soil groups & $\begin{array}{c}\text { Specific gravity } \\
\left(\mathrm{g} / \mathrm{cm}^{3}\right)\end{array}$ & Liquid limit (\%) & Plastic limit $(\%)$ & $\begin{array}{c}\text { Soil } \\
\text { classification }\end{array}$ & $\begin{array}{c}\text { Optimum water } \\
\text { content }(\%)\end{array}$ & $\begin{array}{c}\text { Max. dry density } \\
\left(\mathrm{g} / \mathrm{cm}^{3}\right)\end{array}$ & $\begin{array}{c}\text { Degree of } \\
\text { saturation }(\%)\end{array}$ \\
\hline SS & 2.71 & 28.6 & 8.9 & SM & 15.2 & 1.82 & 58.35 \\
HC & 2.42 & 26.3 & 17.4 & CL & 6.6 & 1.96 & 75.6 \\
HS & 2.65 & 38.7 & 25.4 & CL & 16.9 & 1.77 & 95.5 \\
\hline
\end{tabular}

TABLe 2: Content of different salts in the saline soils.

\begin{tabular}{lccccccccc}
\hline \multirow{2}{*}{ Soil groups } & \multicolumn{4}{c}{ Content of selected salts (weight \%) } & \multicolumn{3}{c}{ Total salt content (\%) } \\
& $\mathrm{CO}_{3}{ }^{2-}$ & $\mathrm{HCO}_{3}{ }^{-}$ & $\mathrm{Cl}^{-}$ & $\mathrm{SO}_{4}{ }^{2-}$ & $\mathrm{Ca}^{2+}$ & $\mathrm{Mg}^{2+}$ & Total & 36.1 \\
$\mathrm{HC}$ & 0.03 & 0.13 & 17.93 & 0.48 & 0.60 & 0.98 & 20.14 & 5.81 & 11.9 \\
$\mathrm{HS}$ & 0.00 & 0.01 & 3.37 & 1.49 & 0.70 & 0.24 & 5.9 \\
\hline
\end{tabular}

\section{Engineering Background}

The Qarhan Salt Lake saline soil area is located in the northeastern part of the Qinghai-Tibet Plateau in the Qaidam Basin. It is an inland basin at the northwestern tip of Qinghai Province, a component of the Central Asian desert, and belongs to the cold zone of the Qinghai-Tibet Plateau in the natural zoning of the highway. The annual precipitation in this area is only $20-143 \mathrm{~mm}$, but the annual evaporation is as high as $2000-3000 \mathrm{~mm}$, and the geographical location is inside the northwestern continent, surrounded by high mountains, making it difficult for warm and humid airflows to enter and being affected by high-temperature sunlight throughout the year. This is a typical continental desert climate; there are a large number of saline soils with more types and complex characteristics. Figure 1 is a map of salt crystals along the roadside of the Qarhan-Golmud Highway, where salt crystals are often seen on the ground surface.

The starting point of the road from Garsu to Golmud is located in Garsu, and the endpoint is located in Golmud City, with a total length of $34.7 \mathrm{~km}$, and various types of saline soils are widely distributed. The major difference between saline soils and general soils is that saline soils contain a certain amount of soluble salts, which are completely dissolved in water when the water content is high, and the supersaturated salts will exist between soil particles in the

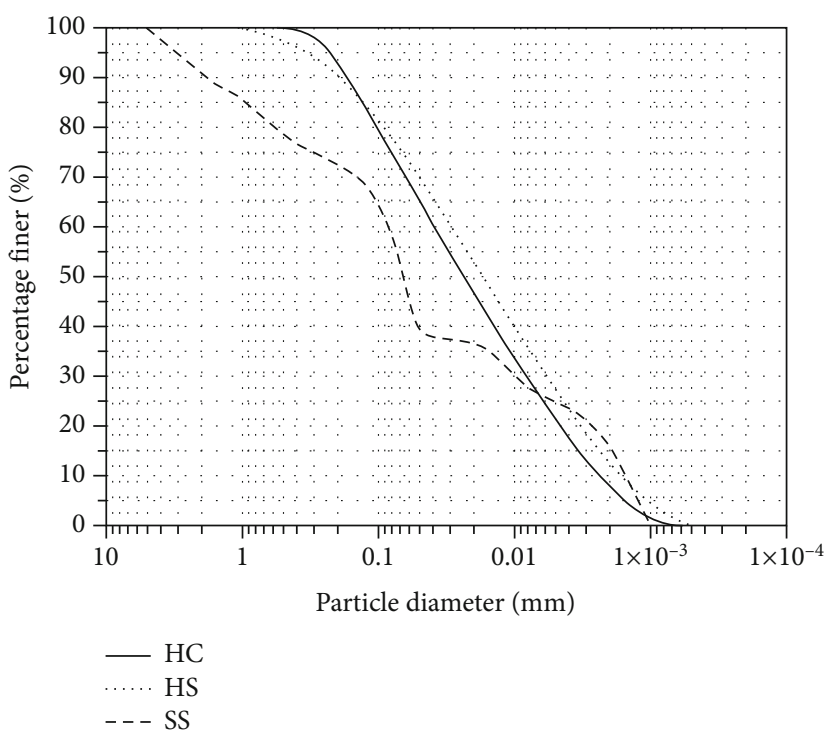

Figure 2: Particle size distribution of three soil samples.

form of crystals when the water content is low, playing a certain skeletal role $[24,25]$. Therefore, saline soils are hard when the water content is low, and there is a certain cementation between the soil particles, possessing a certain bearing capacity. When the external conditions change (rainfall, 


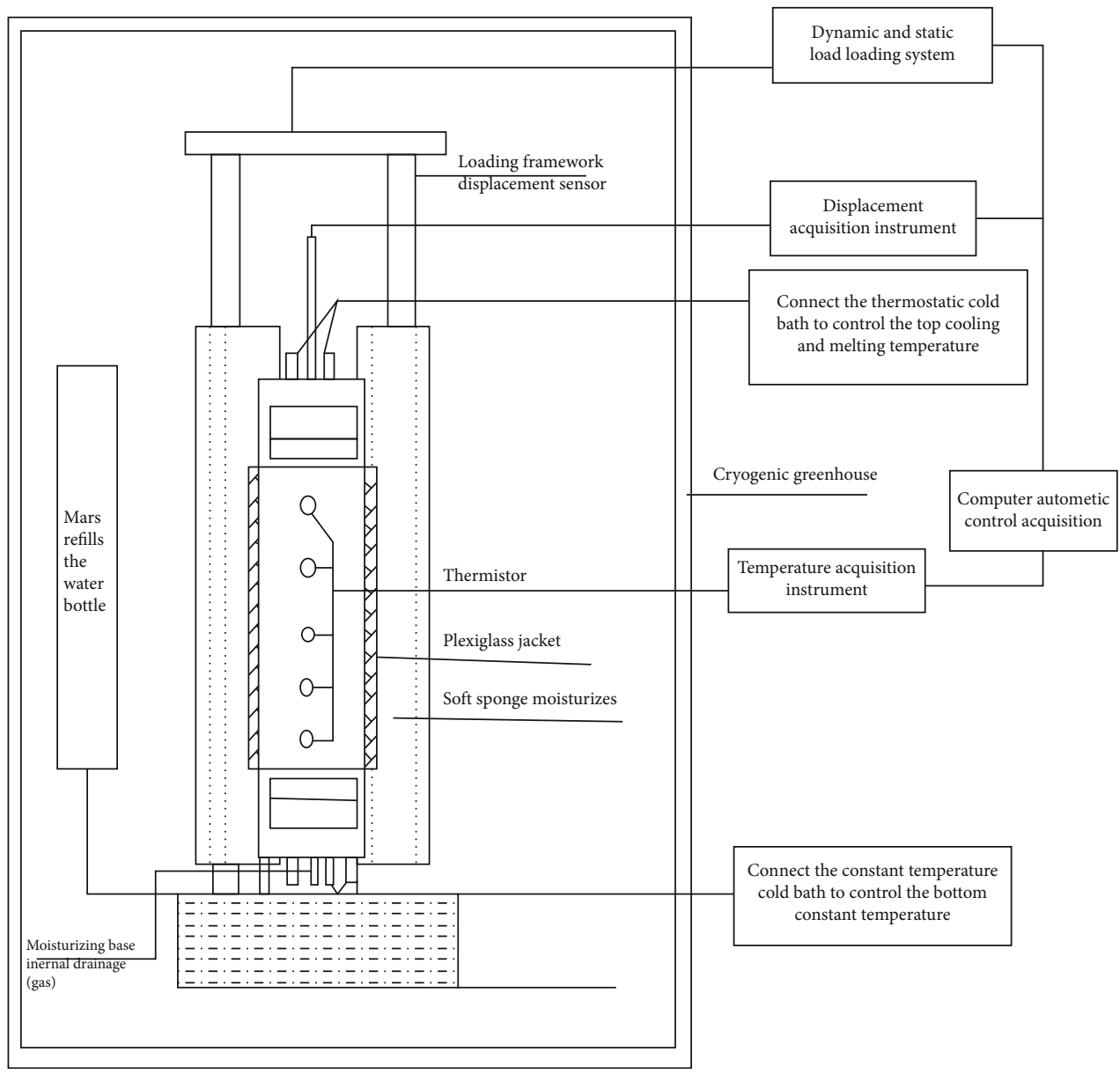

(a)

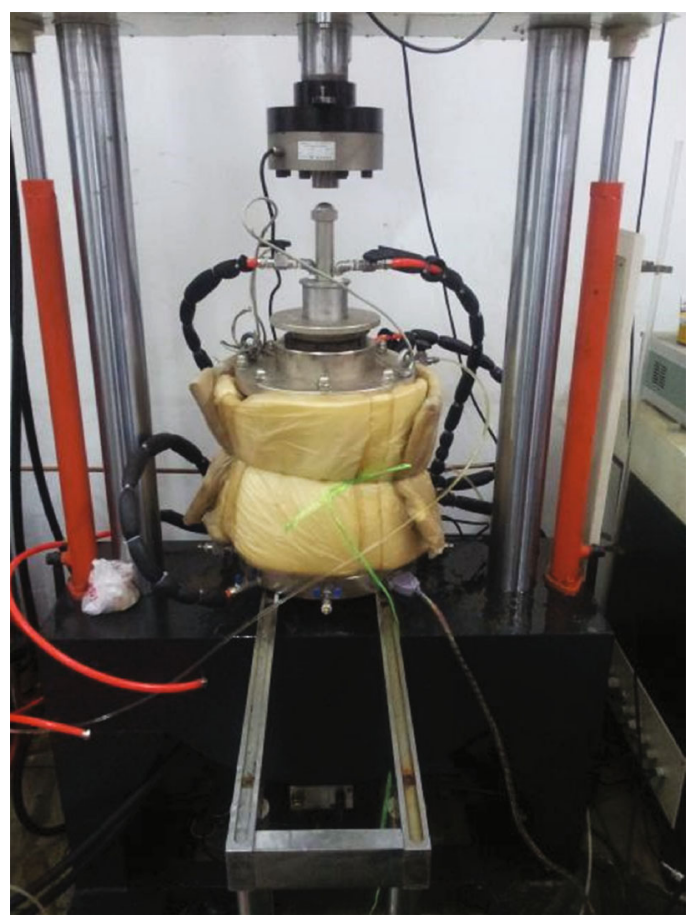

(b)

FIgURE 3: Instrument connection diagram. (a) The instrument connection plan. (b) The loading diagram of the dynamic load experimental device. 
irrigation, etc.), the soluble salt in the soil dissolves completely, and the soil structure is damaged to the extent that the strength decreases, and it is very likely that salt swelling, slurry, sinking and corrosion, and other disaster problems will occur, which are the main types of road diseases in saline soil areas in China [26, 27].

\section{Experimental Design of Soil Column under Dynamic Load}

3.1. Physical Parameters of Soil Samples. For the sandy chalk soil, the roadbed filler from the typical frost swelling and slurry section of National Highway 109 Rubber Mountain in Qinghai Province was used, while the samples of two saline soils were taken from along the Qarhan-Golmud Highway in Qinghai Province and divided into two groups according to the content of chloride salt or sulfate. The soil samples were subjected to basic physical properties and soluble salt chemical tests. The basic parameters of the soil samples are shown in Table 1. The contents of different salts in the two saline soil test soil samples are shown in Table 2. The soil samples were numbered. SS (sandy silt) is a sandy chalky soil, the salts in soil sample HC (high-chloride lowsulfate silty clay) in saline soils are mainly chloride salts with high total salt content, while soil sample HS (high-sulfate low-chloride silty clay) has a relatively high sulfate content. Figure 2 shows the particle size distribution of the three soil samples. According to [28], soil samples HC and HS are low-plasticity fine clay (CL), and soil sample SS is lowliquid limit sandy silt (SM).

3.2. Dynamic Load Test. The test equipment is shown in Figure 3. The specific test steps are as follows:

(1) In this test, a plexiglass cylinder with a diameter of $150 \mathrm{~mm}$ and a wall thickness of $10 \mathrm{~mm}$ was used. A thin layer of petroleum jelly was evenly applied to the cylinder wall, and a plastic bag with an open bottom was pasted along the cylinder wall to ensure water inhalation during the test. Then, the plexiglass cylinder and its matching bottom plate were combined and the plastic bag was made to stick to the top of the plate, and then, the required amount of soil $670.57 \mathrm{~g}$ was calculated according to the compaction degree of 0.96 , and the soil was divided into five layers and put into the plexiglass cylinder, and each layer was compacted according to the requirements. The control height of each layer is $20 \mathrm{~mm}$. After compaction of one layer, the hair should be scraped and then the next layer should be compacted. A piece of filter paper is placed at the top and bottom end of the specimen to act as a water permeable and water impermeable

(2) After the soil sample was prepared, the plate was mounted at the top and the temperature sensor was inserted into the temperature hole. From the top to the bottom cylinder, each inserted a temperature sensor $2 \mathrm{~cm}$. After the specimen was made, the outer

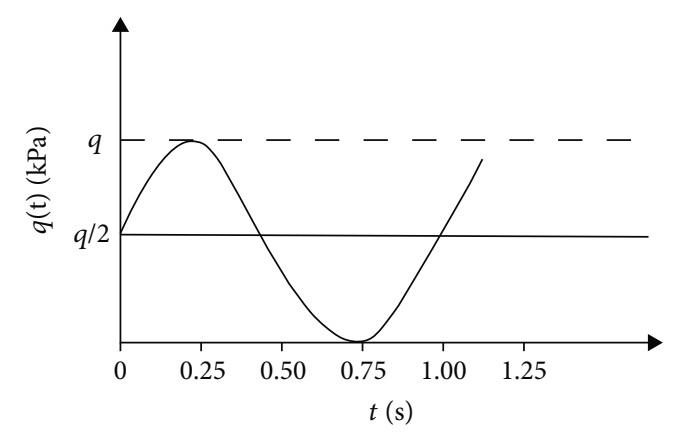

Figure 4: Sine wave cyclic loading.

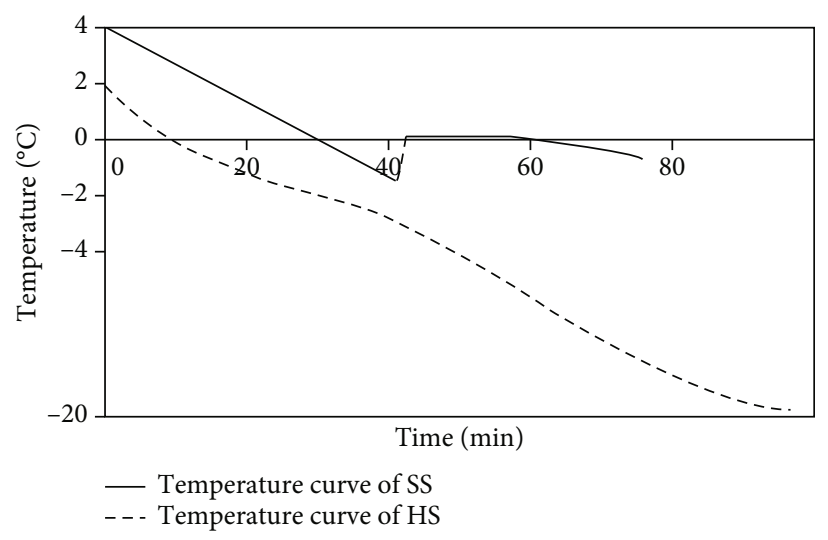

FIGURE 5: Cooling curves of specimens in SS and HS.

layer was wrapped with a sponge to provide insulation and left to stand for 24 hours so that the moisture in the soil sample was evenly distributed

(3) Keep the temperature of the walk-in cryostat chamber at $5^{\circ} \mathrm{C}$ and adjust the sample temperature of the top and bottom plates of the cryostat to $5^{\circ} \mathrm{C}$. The temperature of the soil sample is determined by an internal sensor until the temperature in the soil is $5^{\circ} \mathrm{C}$ from top to bottom

(4) The temperature of the cryostat on the top plate is adjusted to $-10^{\circ} \mathrm{C}$, and the temperature of the bottom plate of the cryostat remains unchanged, allowing one-way cooling; at the same time, static load and dynamic load $(30 \mathrm{kPa}+60 \mathrm{kPa})$ are applied to the top of the soil sample. The pressure sine wave is adjusted to the dynamic load and its frequency is set to $1 \mathrm{~Hz}$, and the load curve is shown in Figure 4. During the experiment; the temperature changes and soil deformation processes of the soil samples were recorded. The experiment ends when the internal temperature stability and deformation of the soil sample are stabilized

The height of the subgrade in this area is about $1.5 \mathrm{~m} \sim 1.8 \mathrm{~m}$. The maximum density of subgrade filler is $1960 \mathrm{~kg} / \mathrm{m}^{3}$ and is taken; it is calculated that the applicable static load for this experiment is $30 \mathrm{kPa}$. The dynamic load 
TABLE 3: Soil test condition.

\begin{tabular}{lccccc}
\hline Soil samples & $\begin{array}{c}\text { Optimum water } \\
\text { content }(\%)\end{array}$ & $\begin{array}{c}\text { Degree of } \\
\text { compaction }(\%)\end{array}$ & $\begin{array}{c}\text { Top cold junction } \\
\text { temperature }\left({ }^{\circ} \mathrm{C}\right)\end{array}$ & $\begin{array}{c}\text { Bottom cold junction } \\
\text { temperature }\left({ }^{\circ} \mathrm{C}\right)\end{array}$ & $\begin{array}{c}\text { Load (static load + dynamic load) } \\
(\mathrm{kPa})\end{array}$ \\
\hline SS & 15.2 & 96 & -10 & 5 & $30+60$ \\
HC & 6.6 & 96 & -10 & 5 & $30+60$ \\
HS & 16.9 & 96 & -10 & 5 & $30+60$ \\
\hline
\end{tabular}

condition in the test is based on [29]; a $20 \mathrm{t}$ vehicle traveling at $60 \mathrm{~km} / \mathrm{h}$ has a peak dynamic stress of $34 \mathrm{kPa}$ on the surface of the subgrade. Combined with the existing test equipment and minimum speed limit of $80 \mathrm{~km} / \mathrm{h}$ on QarhanGolmud Highway, the dynamic load strength is set to $60 \mathrm{kPa}$ in this test.

\section{Results and Discussion}

4.1. Freezing Temperature Test Results. It is verified according to the fitting equation of the freezing temperature of saline soil given by Chen et al. [30]

$$
-T_{d}=2.8752 W^{-1.0509}\left(\mathrm{Cl}^{-}\right)^{0.8427}\left(\mathrm{SO}_{4}^{2}-\right)^{0.3575},
$$

where $W$ is the optimal water content, $\mathrm{Cl}^{-}$is the chloride ion content, and $\mathrm{SO}_{4}{ }^{2-}$ is the sulfate ion content.

Figure 5 is the cooling and freezing time history curve of the test soil sample. It can be known from the test results that the freezing temperature of the $S S$ is $-0.32^{\circ} \mathrm{C}$, and the freezing temperature of HS should be below $-20^{\circ} \mathrm{C}$.

According to Equation (1), the greater the chloride ion content, the lower the freezing temperature of soil. The content of the major negative ions in the soil sample was brought into Equation (1), the theoretical freezing temperature of the $\mathrm{HS}$ is $-23^{\circ} \mathrm{C}$, and the salt content of $\mathrm{HC}$ is higher than that of HS, so the freezing temperature of $\mathrm{HC}$ should be much less than $-23^{\circ} \mathrm{C}$.

4.2. Temperature Gradient Test Results. In the process of simulating the temperature gradient cooling of the field roadbed, all three types of soil samples were subjected to dynamic load tests during the temperature gradient cooling process at the optimum moisture content and $96 \%$ compaction. The height of the test soil sample is $10 \mathrm{~cm}$, the top is the cold end (target temperature $-10^{\circ} \mathrm{C}$ ), and the bottom of the soil sample is the warm end (target temperature $5^{\circ} \mathrm{C}$ ); under the effect of this temperature gradient, the soil sample characteristics, temperature gradient, and dynamic loading test conditions are shown in Table 3.

As the experiment progresses, the internal temperature of the soil will gradually change. The time course diagrams of temperature variation and temperature gradient diagrams of the three soil samples are shown in Figures 6-8.

Figure 6 shows the change process of the temperature field during the freezing process of sandy silt soil samples. During the first period of cooling, the temperature changes rapidly, but as time goes by, the temperature tends to stabilize. It was also found that the freezing temperature $\left(-0.32^{\circ} \mathrm{C}\right)$ line is at a distance of about $8.6 \mathrm{~cm}$ from the top and the $0^{\circ} \mathrm{C}$

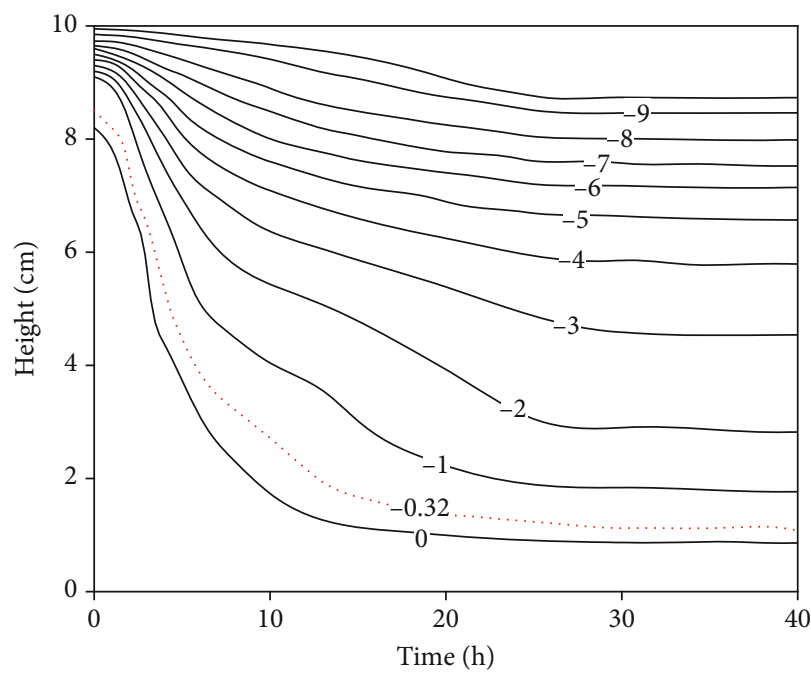

FIgURE 6: Temperature change process of SS.

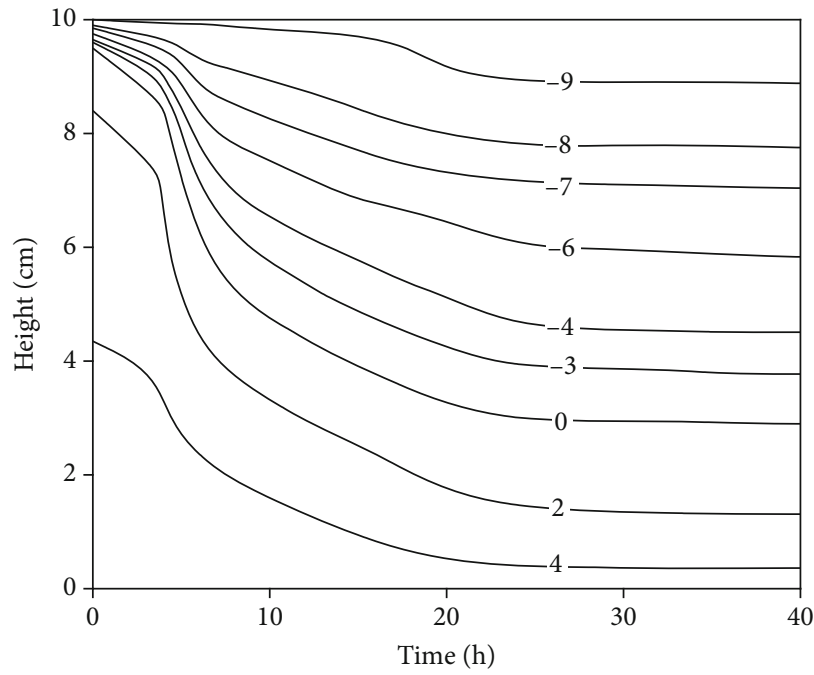

Figure 7: Temperature change process of HC.

line is at a distance of about $8.9 \mathrm{~cm}$ from the top when the temperature tends to stabilize.

Figures 7 and 8 show the temperature time history change curves of HC and HS soil samples during freezing process, and their temperature time history changes are similar. It can be seen from the temperature time history chart that the temperature changes very quickly during the first period of cooling, but as time goes by, the temperature tends to stabilize. However, since the HC and HS soils will not 


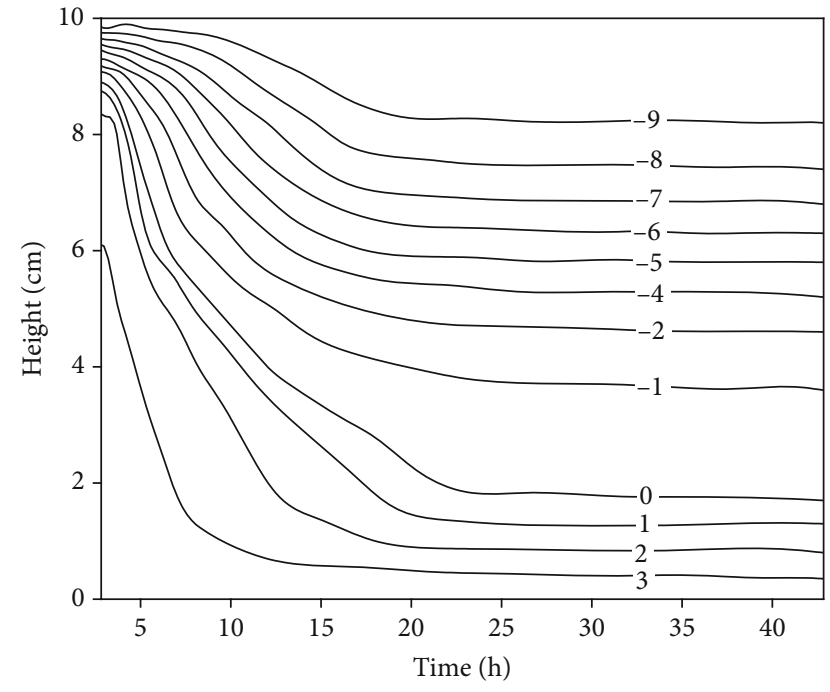

Figure 8: Temperature change process of HS.

freeze during the temperature gradient cooling process, the water in the soil migrates to the cold end at a slower rate than the SS soil, and the migration distance is also longer than that of the SS soil, so it shows the cooling process of SS is also slower than that of SS soil. After the temperature is stabilized, the distance between the $0^{\circ} \mathrm{C}$ line of $\mathrm{HC}$ soil and the top was $6.3 \mathrm{~cm}$, and the distance between the $00^{\circ} \mathrm{C}$ line of HS soil and the top was $7.6 \mathrm{~cm}$.

Therefore, the three types of soil samples under the same temperature gradient cooling effect all show a faster cooling rate in the early stage, and the temperature gradient change tends to be stable after about 40 hours of the test. However, due to the influence of the freezing temperature and water content of the soil, the temperature is lowered. The velocity and isotherm position are quite different.

\subsection{Test Results of Soil Deformation under the Coupling} Action of Cooling and Dynamic Load. The change rate of deformation, that is $\Delta h / H(\Delta h)$ to the original height of the soil $(H)$. According to Figure 9, it is the ratio of the amount of change in the height of the soil column to the initial height of the soil column during a certain test time. HC and HS do not freeze under the effect of this cooling process; therefore, the deformation of these two soil samples is caused by salt type and dynamic load.

Deformation rate, that is $\Delta h / \Delta t$, change of soil sample height per unit time reflects the change of soil deformation gradient.

The soil deformation under the dynamic load of SS (sandy silt) can be seen from Figure 10. In the rapid freezing zone and transition zone, the gradient of the soil sample's frost heave curve is relatively large. The amount of swelling is getting larger and larger, but the gradient of the curve gradually decreases, and finally, the amount of frost heaving of the soil tends to stabilize at about $1 \%$. The frost heave rate of SS is shown in Figure 11. It can be seen from the figure that the frost heave rate of the soil sample increases first and then decreases with time. In the first few hours, the soil

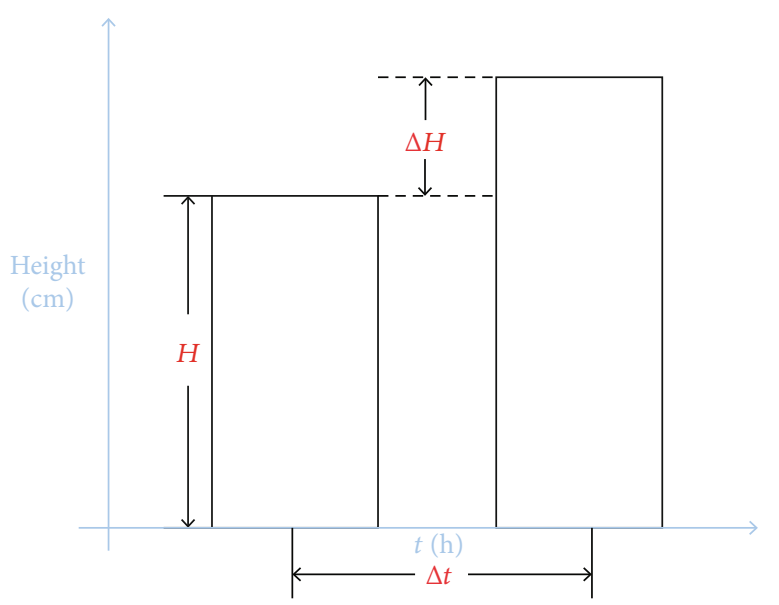

FIgURE 9: Schematic diagram of calculated parameters of soil column.

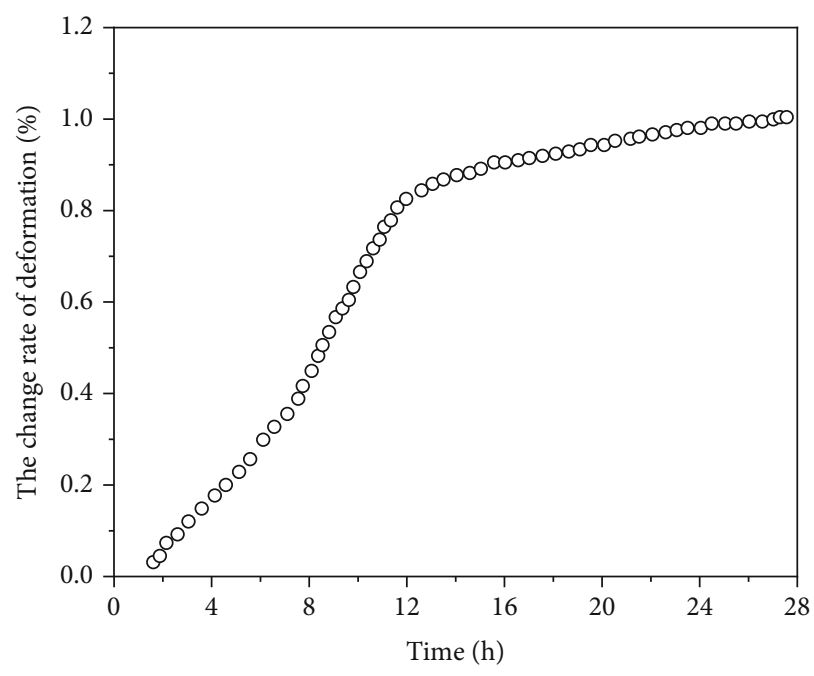

FIgURE 10: The change rate of deformation vs. time for SS.

sample is in a state of rapid freezing, and the frost heaving rate gradually increases and reaches the maximum value. After entering the freezing transition zone and freezing-like stable zone, the water in the unfrozen zone in the soil sample migrates to the frozen zone, and the change rate of deformation gradually decreases until it finally stabilizes.

The curve of soil deformation rate versus time for $\mathrm{HC}$ under dynamic load can be seen in Figure 12. Under dynamic load, in the initial stage of cooling loading, the deformation is larger, and it is mainly due to the compression deformation of soil caused by static load and dynamic load; into the late stage of loading, its deformation rate tends to stabilize, and the final deformation rate is stabilized at $-1.10 \%$; the main reason for the decrease in soil deformation rate is the compression of soil voids prompted by dynamic load, in addition to the small salt shrinkage contraction deformation of the HC saline soil itself due to the decrease in temperature [31]. Figure 13 shows the deformation rate graph of HC, and it can be seen that the salt expansion rate varies greatly at the beginning of the test; however, it tends 


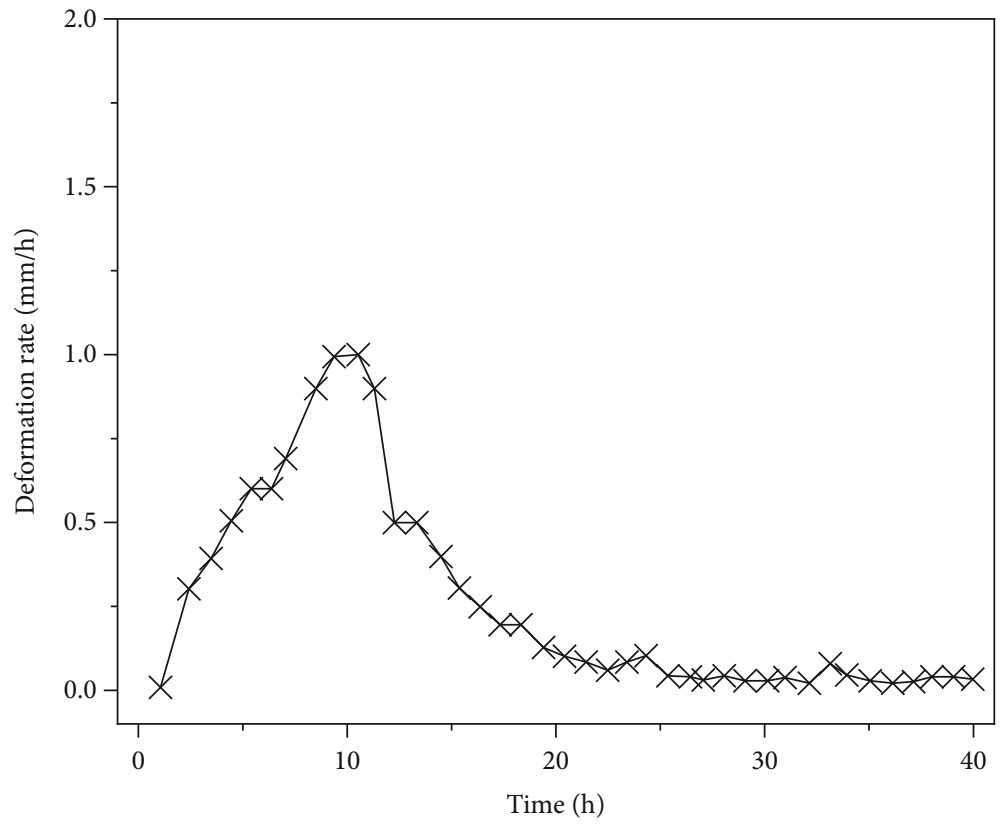

Figure 11: Deformation rate vs. time for SS.

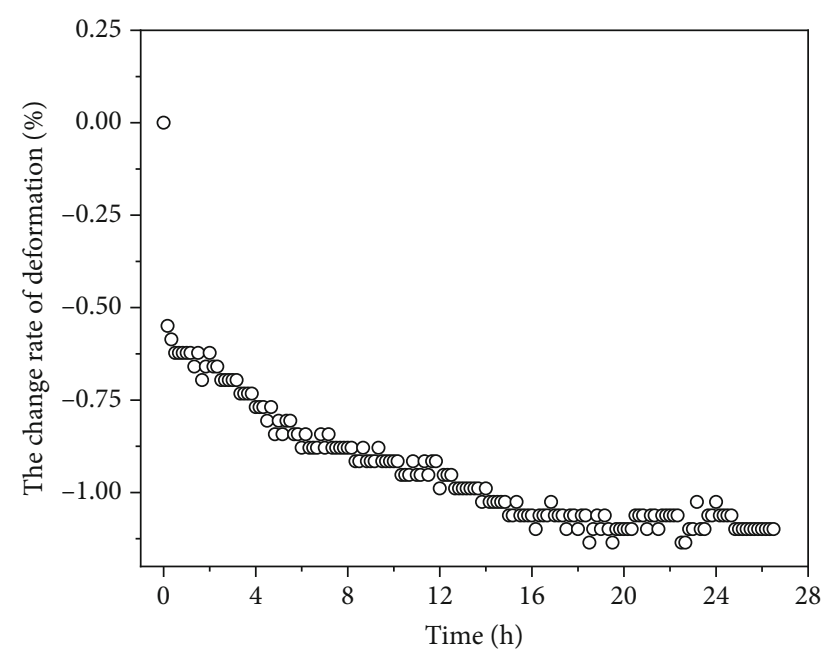

FIgURE 12: The change rate of deformation vs. time for soil HC.

to level off for a period of time and then tends to decrease until finally leveling off. This is because at the beginning of the test, the soil is not highly compacted, and there are still more soil particle voids. After that, as the test proceeded, the soil temperature changed and salt shrinkage occurred in the saline soil, after which it tended to level off.

The relationship curve between soil deformation and time of the HS test soil sample under dynamic load can be seen in Figure 13. Under the action of dynamic load, the soil deformation rate is $-0.73 \%$, showing settlement. The initial stage of deformation is also due to the compression deformation of the soil caused by static load and dynamic loading. However, because HS soil samples contain more sulfates, during the cooling process, although the soil does not freeze, when the temperature drops to $15^{\circ} \mathrm{C}$, the $\mathrm{Na}_{2} \mathrm{SO}_{4}$ in the soil begins to crystallize into $\mathrm{Na}_{2} \mathrm{SO}_{4} \cdot 10 \mathrm{H}_{2} \mathrm{O}$, the volume of the salt crystals. The growth rate reached 320\% [32]. The salt swelling force in the soil can be balanced in a part of the dynamic load and finally lead to a settlement less than the HC soil sample. Figure 14 and 15 show the change rate of deformation and deformation rate for HS, which has a similar trend to HC. In the early stage of loading, the deformation rate increases rapidly with time and then enters a stable state. In the same way, at the initial stage of soil deformation, the originally existing soil particle interstices are compacted due to the $96 \%$ compaction. As the temperature decreases, salt crystallization begins to occur in the soil, which increases the volume of the soil. Finally, after the crystallization reaches equilibrium, the internal deformation of the soil tends to be smooth and no major changes occur.

\section{Model Analysis}

\subsection{The Change Rate of Deformation and Time Model}

(1) The change rate of deformation and time model of sandy silt

Figure 16 shows the deformation rate and time model of SS. The red curve is the fitted curve, and the white origin is the experimental data. The equation can be fitted according to the test results:

$$
y=(a x-b) \cdot e^{(c x+b)} .
$$

In the equation, $y$ is the deformation rate, $x$ is the time, and $a, b$, and $c$ are the test parameters, fitting to get $a=$ $0.14264, b=0.26069, c=-0.00598$, and $R^{2}=0.9772$.

(2) The change rate of deformation and time model of saline soil 


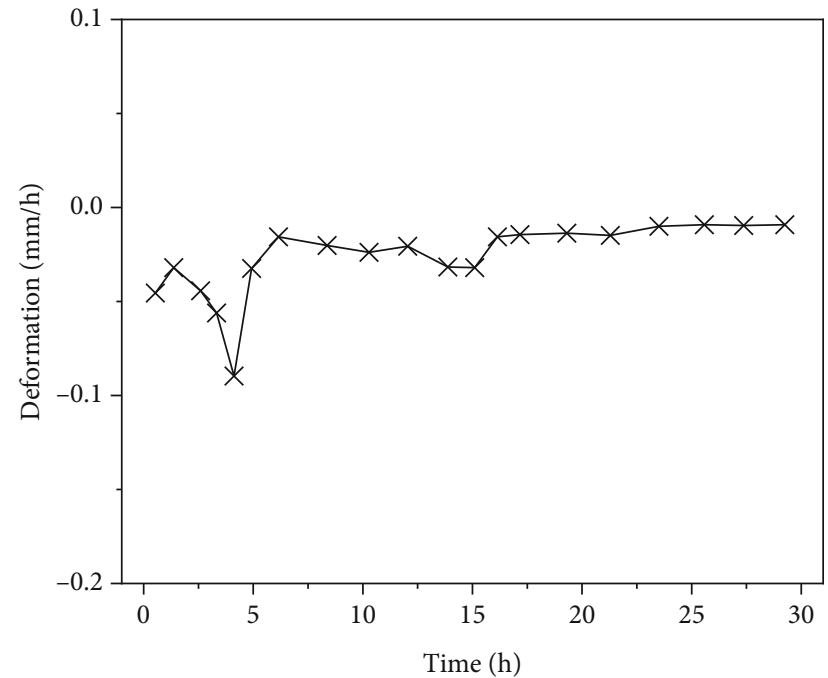

FIgURE 13: Deformation rate vs. time for soil HC.

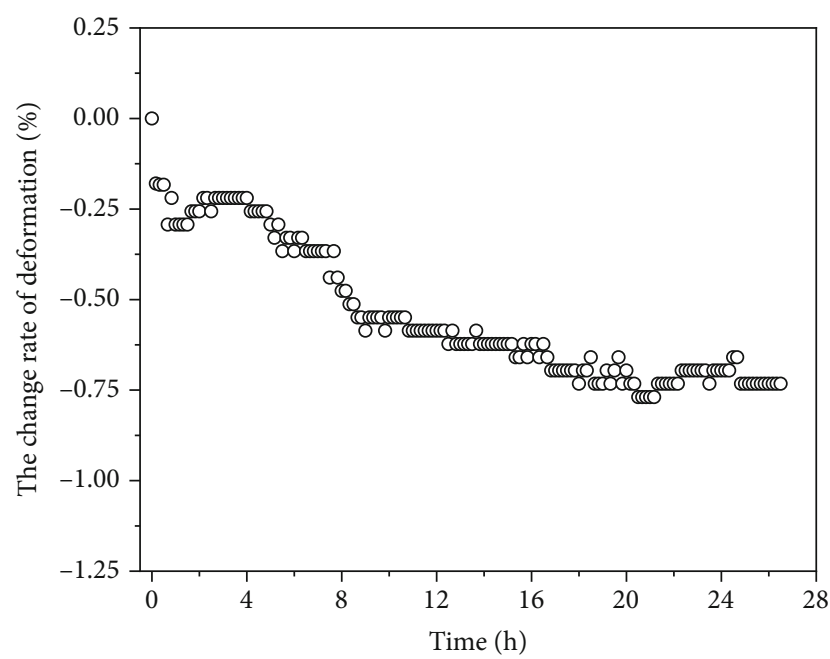

FIGURE 14: The change rate of deformation vs. time for soil HS.

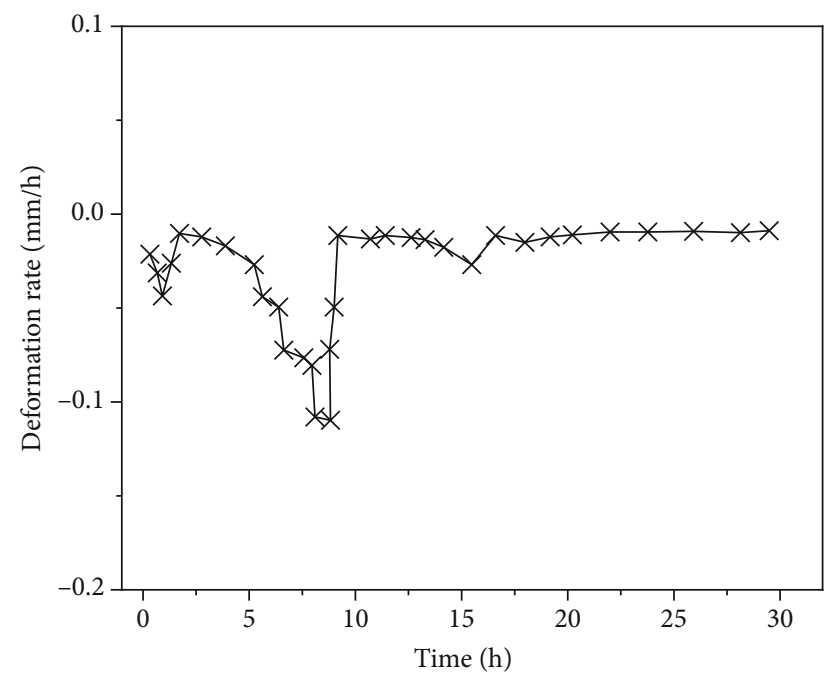

FIGURE 15: Deformation rate for soil HS.

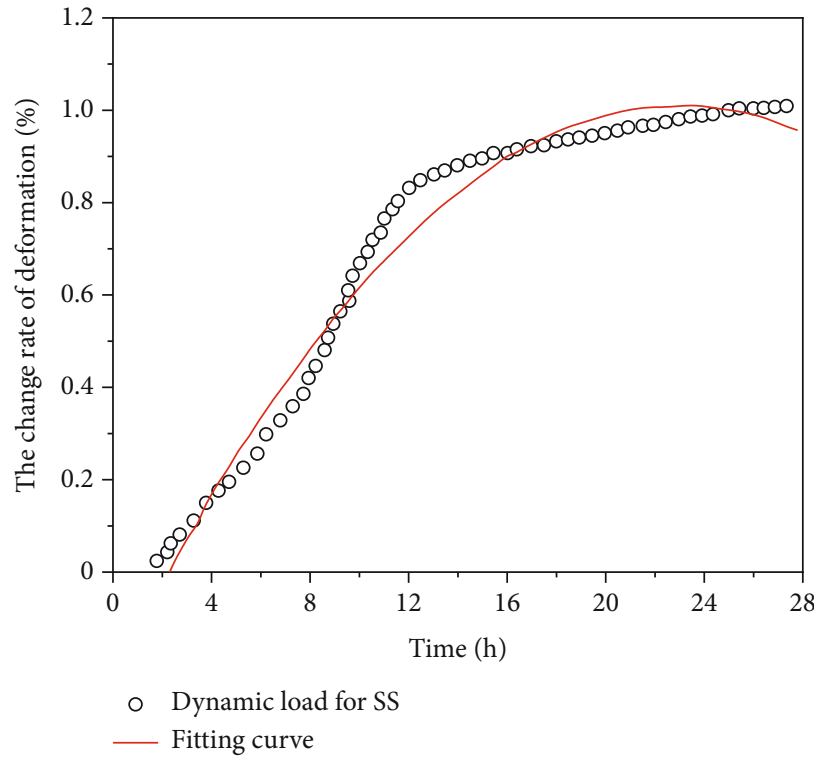

FIGURE 16: The change rate of deformation and time fitting curve of SS.

Figures 17 and 18 are, respectively, the deformation rate and time model diagrams of $\mathrm{HC}$ and HS. The red curve is the fitted curve, and the white origin is the experimental data. The equation can be fitted according to the test results:

$$
y=A x+B x^{2}+b
$$

The fitting parameters of $\mathrm{HC}$ and $\mathrm{HS}$ are shown in Table 4.

\subsection{The Change Rate of Deformation and Deformation Rate Model}

(1) The change rate of deformation and deformation rate model of sandy silt

Figure 19 shows the relationship between the freezing rate and frost heave rate of sandy silt. It can be seen that when the top cooling temperature is constant, the freezing rate of the soil sample decreases with the increase of the frost heave rate.

According to the test results, the following equation can be fitted:

$$
\varepsilon_{\mathrm{SS}}=l_{\mathrm{SS}} e^{m_{\mathrm{SS}} v_{\mathrm{SS}}},
$$

where $\varepsilon_{\mathrm{SS}}$ is the strain of SS soil (\%); $v_{\mathrm{SS}}$ is the freezing rate of SS soil $(\mathrm{mm} / \mathrm{h}) ; l$ and $m$ are the experimental parameters related to load, temperature, and soil properties. The experimental results fit the value of $l_{\mathrm{SS}}$ to 29.38409 and the value of $m_{\mathrm{SS}}$ to -0.16089 .

It can also be seen from the above figure that the greater the freezing rate, the smaller the frost heave rate; the smaller the freezing rate, the greater the frost heave rate, and the relationship between the two is inversely 


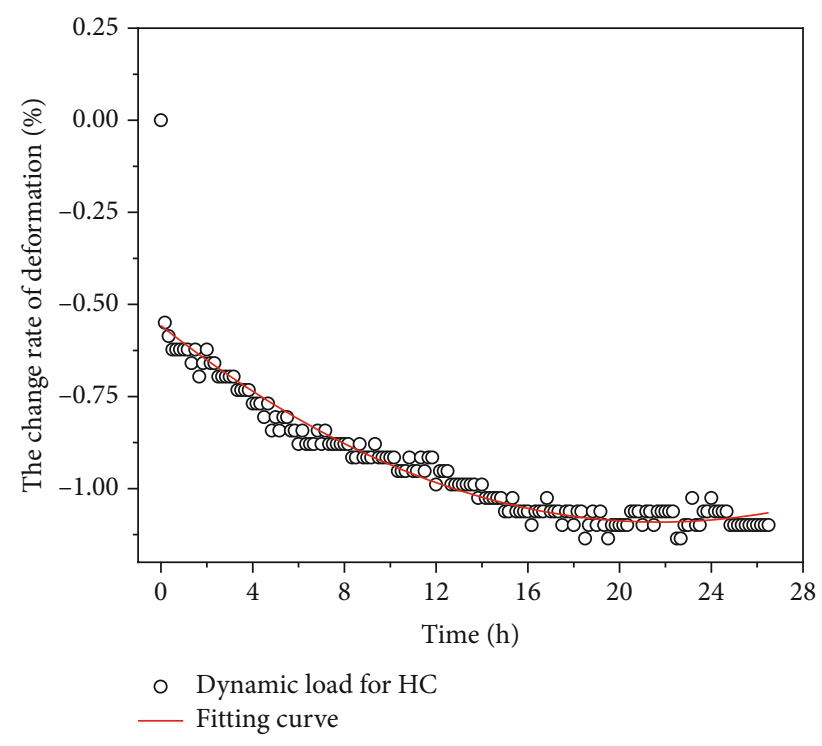

FIGURE 17: The change rate of deformation and time fitting curve of soil HC.

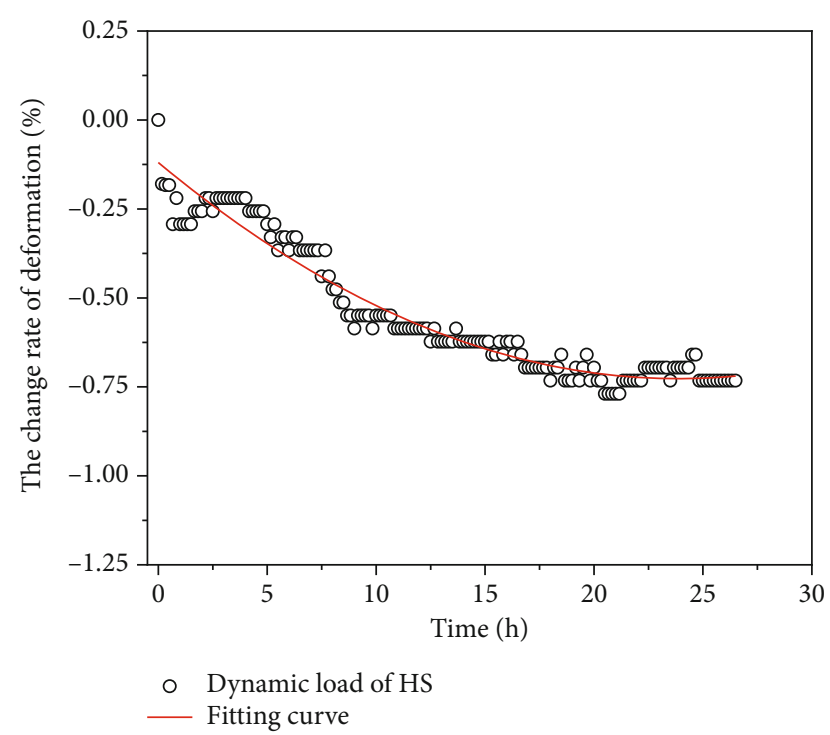

FIGURE 18: The change rate of deformation and time fitting curve of soil HS.

TABle 4: The change rate of deformation and time fitting parameter value of saline soil.

\begin{tabular}{lcccc}
\hline Soil samples & $A$ & $B$ & $b$ & $R^{2}$ \\
\hline HC & -0.0491 & 0.00113 & -0.55744 & 0.90308 \\
HS & -0.05089 & 0.00107 & -0.11954 & 0.94499 \\
\hline
\end{tabular}

proportional. This shows that when the freezing rate is small, the freezing front moves slowly, and the increase in freezing depth is small, but at this time, the frost heave rate of the soil sample is very large, resulting in the formation of ice lenses.

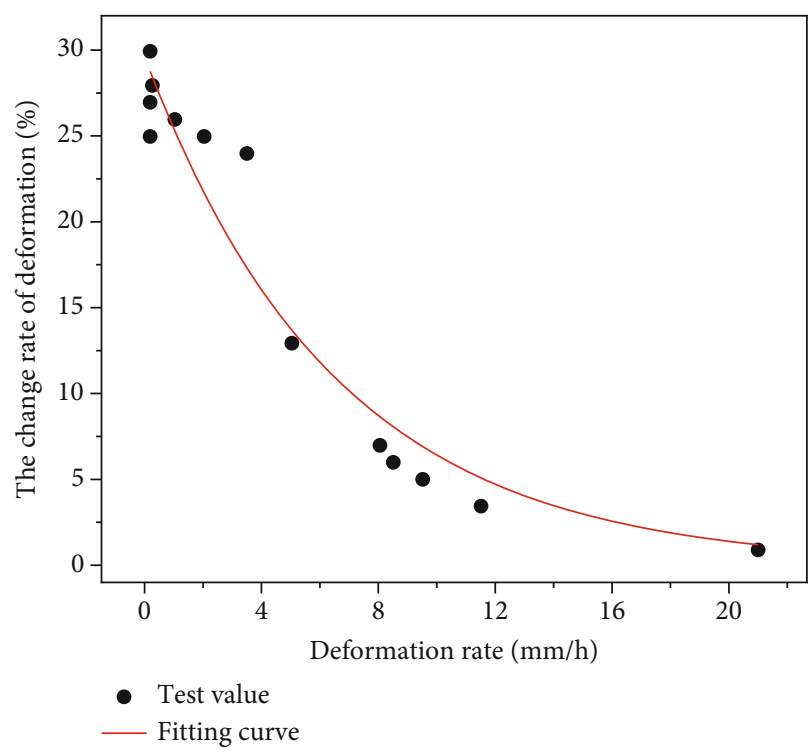

FIGURE 19: Relation between the change rate of deformation and deformation rate of SS.

(2) The change rate of deformation and deformation rate model of saline soil

Figure 20 shows the relationship between the salt swelling rate and instantaneous strain of $\mathrm{HC}$. It can be seen that the instantaneous strain of the soil sample decreases with the increase of the salt expansion rate, and the equation can be fitted according to the test results:

$$
\varepsilon_{\mathrm{HC}}=l_{\mathrm{HC}} e^{m v_{\mathrm{HC}}}
$$

where $\varepsilon_{\mathrm{HC}}$ is the strain of $\mathrm{HC}$ soil (\%); $v_{\mathrm{HC}}$ is the frost heave rate of $\mathrm{HC}$ soil $(\mathrm{mm} / \mathrm{h})$. The experimental results fit the value of $l_{\mathrm{HC}}$ to 0.02832 and the value of $m_{\mathrm{HC}}$ to -12.49289 .

Figure 21 shows the relationship between HS salt swelling rate and instantaneous strain. It can be seen that the instantaneous strain of the soil sample decreases with the increase of the salt expansion rate and finally tends to be flat. The equation can be fitted according to the test results:

$$
\varepsilon_{\mathrm{HS}}=l_{\mathrm{HS}} e^{m_{\mathrm{HS}} v_{\mathrm{HS}}},
$$

where $\varepsilon_{\mathrm{HS}}$ is the strain of HS soil (\%); $v_{\mathrm{HS}}$ is the frost heave rate $(\mathrm{mm} / \mathrm{h})$. The numerical results fit the value of $l_{\mathrm{HS}}$ to 0.0324 and the value of $m_{\mathrm{HS}}$ to -8.59993 .

The fitting parameter values of the three experimental soils are shown in Table 5.

The distribution of salts in the soil sample is more inhomogeneous in high-salinity saline soils, and the sensitivity and dispersion of their phase change and water-salt migration under cooling conditions are more obvious than those of nonsaline soils, making the model fitting effect of highsalinity saline soils (HC and HS) lower than that of SS. 


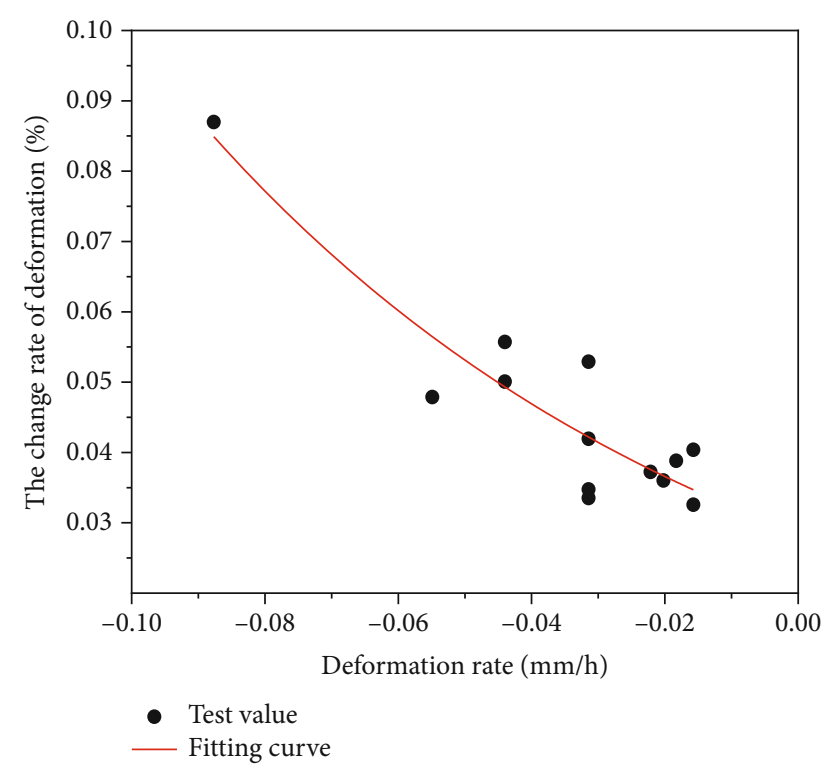

FIGURE 20: Relation between the change rate of deformation and deformation rate of HC.

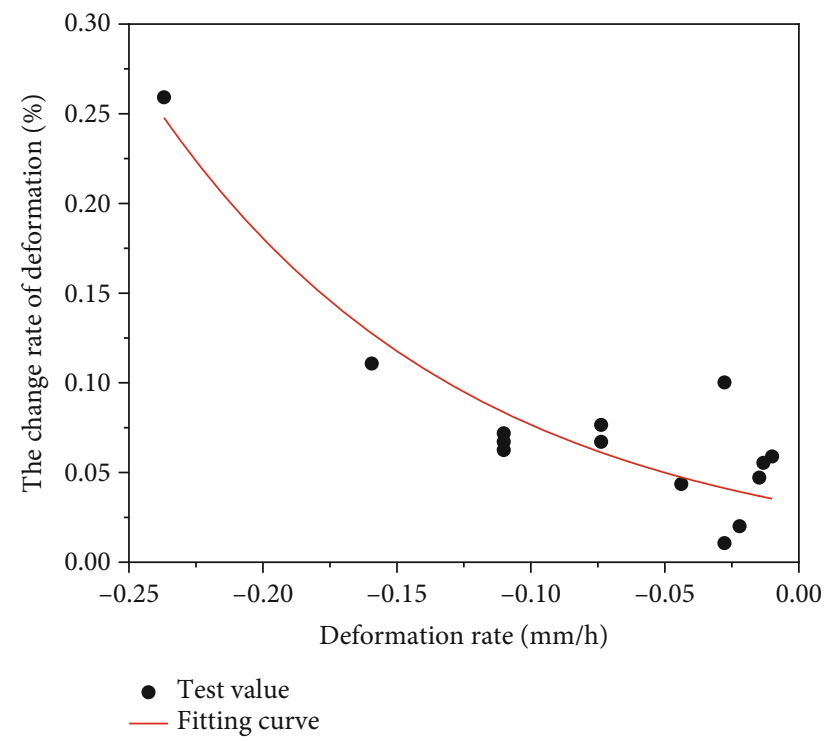

FIGURE 21: Relation between the change rate of deformation and deformation rate of HS.

TABle 5: Parameter values of three experimental soil fittings.

\begin{tabular}{lccc}
\hline Soil types & $l$ & $m$ & $R^{2}$ \\
\hline SS & 29.38409 & -0.16089 & 0.9531 \\
HC & 0.02832 & -12.49289 & 0.8422 \\
HS & 0.0324 & -8.59993 & 0.8389 \\
\hline
\end{tabular}

\section{Conclusions}

From the above research on the deformation characteristics of saline soil and sandy silt under dynamic load, the following conclusions can be drawn:
(1) Under the same temperature gradient cooling effect, the three types of soil samples all show a faster cooling rate in the early stage, and the temperature gradient change tends to be stable after about 40 hours of the test. Due to factors such as the freezing temperature and water content of the soil, the cooling rate and the location of the isotherm are quite different, the freezing temperature $\left(-0.32^{\circ} \mathrm{C}\right)$ line of $\mathrm{SS}$ is near $8.6 \mathrm{~cm}$ from the top, and the $0^{\circ} \mathrm{C}$ line is near $8.9 \mathrm{~cm}$ from the top; the $0^{\circ} \mathrm{C}$ line of $\mathrm{HC}$ is at a distance of $6.3 \mathrm{~cm}$ from the top; the $0^{\circ} \mathrm{C}$ line of $\mathrm{HS}$ is at a distance of $7.6 \mathrm{~cm}$ from the top. Affected by test result of freezing temperature and salt content, $\mathrm{HC}$ and HS will not freeze during the one-way cooling test process. The water in the soil migrates to the cold end at a slower rate than SS, and the migration distance is also longer than that of SS, so its cooling process is also slower than that of SS

(2) Affected by freezing temperature and salt type, SS, $\mathrm{HC}$, and HS show different deformation characteristics. SS showed frost heave of $1.0 \%$, and HC and HS occurred settlement of $-0.73 \%$ and $-1.10 \%$, respectively. In addition, salt expansion effect is caused by the presence of high sodium sulfate in HS and the action of cooling, which will balance part of settlement due to the action of dynamic load, so the deformation of HS is smaller than that of HC

(3) According to the deformation characteristics of SS, $\mathrm{HC}$, and HS, the model of deformation rate vs. time and the model of change rate of deformation vs. deformation rate under coupling action of dynamic load and one-way cooling are given and verified

\section{Data Availability}

The [DATA TYPE] data used to support the findings of this study are included within the article.

\section{Conflicts of Interest}

The authors declare that they have no conflicts of interest.

\section{Acknowledgments}

The work herein is funded by the National Natural Science Foundation of China (No. 41501062) and the Longyuan Youth Innovation and Entrepreneurship Talent (Team) Project of Gansu Province. This support is much appreciated.

\section{References}

[1] B. K. Akoto and A. G. Singh, "Behavior of lime-stabilized laterite under repeated loading," Australian Road Research, vol. 16, no. 4, pp. 259-267, 1986.

[2] C. J. Xu and H. B. Zhou, "Establishment of pore water pressure model of saturated soft clay under undrained cyclic loading," Shanghai Geology, vol. 63, no. 3, pp. 16-20, 1997. 
[3] T. Pritz, "Frequency dependences of complex moduli and complex Poisson's ratio of real solid materials," Journal of Sound and Vibration, vol. 2146, no. 1, pp. 83-1044, 1998.

[4] S. N. Zhang, Laboratory Study on Lime-Improved Expansive Soil, Hohai University, 2005.

[5] S. L. Li and Q. N. Zhou, "Experimental research on dynamic properties of fly ash for embankment filling," Rock and Soil Mechanics, vol. 26, no. 2, pp. 311-314, 2005.

[6] J. Zhang, Y. M. Lai, J. Li, and Y. Zhao, "Study on the influence of hydro-thermal-salt-mechanical interaction in saturated frozen sulfate saline soil based on crystallization kinetics," International Journal of Heat and Mass Transfer, vol. 146, p. $118868,2020$.

[7] C. Wang, Y. Lai, F. Yu, and S. Li, "Estimating the freezingthawing hysteresis of chloride saline soils based on the phase transition theory," Applied Thermal Engineering, vol. 135, no. 4, pp. 22-33, 2018.

[8] M. M. Darrow, S. L. Huang, Y. Shur, and S. Akagawa, "Improvements in frost heave laboratory testing of finegrained soils," Journal of Cold Regions Engineering, vol. 22, no. 3, pp. 65-78, 2008.

[9] X. D. Zhang, Q. Wang, T. W. Yu, G. Wang, and W. Wang, "Numerical study on the multifield mathematical coupled model of hydraulic-thermal-salt-mechanical in saturated freezing saline soil," International Journal of Geomechanics, vol. 18, no. 7, p. 04018064, 2018.

[10] Y. H. Tian, J. K. Liu, and L. Y. Peng, "Experimental study on frost action of fine-grained soils under dynamic and static loads," Chinese Journal of Geotechnical Engineering, vol. 32, no. $12,2010$.

[11] J. Zhou, X. N. Gong, and J. Q. Li, "Experimental study of saturated soft clay under cyclic loading," Industrial Construction, vol. 30, no. 11, pp. 43-47, 2000.

[12] Y. C. Ye and X. H. Lai, "Dynamic strength characteristics of silt in the Hangzhou Bay," Marine Sciences, vol. 27, no. 2, pp. 56$59,2003$.

[13] J. Zhou, "Research on cyclic deformation of saturated soft clay," Chinese Journal of Geotechnical Engineering, vol. 22, no. 4, pp. 499-502, 2000.

[14] L. Matesic and M. Vucetic, "Strain-rate effect on soil secant shear modulus at small cycle strains," Journal of Geotechnical and Geoenvironmental Engineering, vol. 169, no. 6, pp. 536549, 2003.

[15] V. K. Khosla and R. D. Singh, "Influence of number of cycles on strain," Canadian Geotechnical Journal, vol. 15, no. 4, pp. 584-592, 1978.

[16] T. Sarkar and M. Mishra, "Soil erosion susceptibility mapping with the application of logistic regression and artificial neural network," Journal of Geovisualization and Spatial Analysis, vol. 2, no. 1, pp. 8-9, 2018.

[17] S. S. Zhang, Y. W. Wang, L. Zhang, X. H. Yang, and W. Z. Chen, "Influence factors of the effect of the load on the salt expansion suppression for coarse-grained saline soil under the interaction of multiple factors," Journal of Applied Basic Science and Engineering, vol. 27, no. 5, pp. 185-196, 2019.

[18] F. T. Zhao, L. J. Chang, and W. Y. Zhang, "Study on the dynamic stress-strain response of subgrade saline soil under temperature change condition," Railway Standard Design, vol. 63, no. 5, pp. 54-59, 2019.

[19] X. Y. Zhang, M. Y. Zhang, J. G. Lu, W. Pei, and Z. Yan, "Effect of hydro-thermal behavior on the frost heave of a saturated silty clay under different applied pressures," Applied Thermal Engineering, vol. 117, pp. 462-467, 2017.

[20] X. Zhang, M. Zhang, W. Pei, and J. Lu, "Experimental study of the hydro-thermal characteristics and frost heave behavior of a saturated silt within a closed freezing system," Applied Thermal Engineering Design Processes Equipment Economics, vol. 129, no. 5, 2018.

[21] L. Q. Li, Basic Knowledge of Saline Soil, Science Press, 1986.

[22] Q. C. Yu, W. Sun, B. Chen, L. Yang, and G. Zhang, "Research on strength of Song-Nen Plain soda-saline soil," Rock and Soil Mechanics, vol. 29, no. 7, pp. 1793-1796, 2008.

[23] Y. Zhang, J. Fang, J. Liu, and A. Xu, "Research on the distribution of saline soil along the Qarhan-Golmud Highway, Northwestern China," Sciences in Cold and Arid Regions, vol. 7, no. 2, pp. 189-193, 2015.

[24] S. X. Chai, B. Z. Yang, X. Y. Wang, P. Wang, X. M. Zhong, and L. Wei, "Experimental research on effect of salt content on strength of solidified saline soil in inshore with lime," Rock and Soil Mechanics, vol. 7, pp. 50-53, 2008.

[25] F. Zhang, X. Q. Hu, Y. W. Liu, G. L. Xu, and X. Q. Zhan, "Experimental study on the influence of salt content on the shear strength of sulfated saline soil," Railway Construction, vol. 6, pp. 162-164, 2014.

[26] C. X. Yu, Experimental Study on Unsaturated Properties of Inland Sulfate Saline Soil, Lanzhou University, 2013.

[27] X. Zhang, E. Zhai, Y. Wu, D.'. Sun, and Y. Lu, “Theoretical and numerical analyses on hydro-thermal-salt-mechanical interaction of unsaturated salinized soil subjected to typical unidirectional freezing process," International Journal of Geomechanics, vol. 21, no. 7, 2021.

[28] JTG3430-2020, The Test Methods of Soils for Highway Engineering, P.R. Ministry of Communications Press, China, 2020.

[29] Z. H. Jun-Ming, L. I. Song-Yu, S. H. Ming-Lei, and Z. Haijun, "Experimental study on dynamic response of low embankment under traffic load," Journal of Southeast University (Natural Science Edition), vol. 37, no. 5, pp. 921-925, 2007.

[30] X. B. Chen, J. K. Liu, H. X. Liu, and Y. Q. Wang, Freezing Effect of Soil and Foundation, Science Press, 2006.

[31] Y. Zhang, Z. H. Yang, J. K. Liu, and J. Fang, "Impact of cooling on shear strength of high salinity soils," Cold Regions Science and Technology, vol. 141, pp. 122-130, 2017.

[32] Y. Zhang, J. K. Liu, J. H. Fang, and A. Xu, "Deformation properties of chloride saline soil under action of a low-temperature environment and different loads," Science in Cold and Arid Regions, vol. 9, no. 3, pp. 307-311, 2017. 